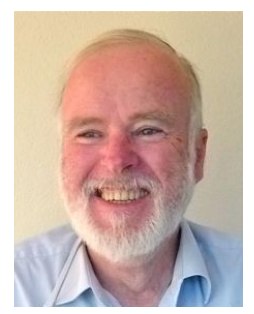

\title{
THE RISKS OF USING REDD+ TO MANAGE RICH SOCIO-ECOLOGICAL SYSTEMS
}

\section{Paul Martin}

Australian Centre for Agriculture and Law

University of New England, Australia ${ }^{1}$

REDD+ is an important development in environmental and social justice policy instruments. However, its success depends on a network of complex contingencies, and the achievement of difficult governance transformations in countries that are under severe economic pressure. It ought be obvious that there are significant risks associated with this endeavour, but overt risk management, using standard approaches, is not evident.

This paper highlights some of the many risks that the governance of REDD+ (in common with most environmental policy innovations) needs to pay attention to in order to avoid policy failure. There are eight distinct elements that have to work for the REDD+ program to achieve its public policy goals, and each of these carries its own risk. These are: securitisation of carbon sequestration; protection for complex non-carbon values, ensuring the integrity of the supply of credit; multilevel administration and aggregation of tradeable carbon interests; managing the social and economic imbalance of interests; deploying new methods for measurement and securitisation of interests; ensuring a platform of rules, administrative and enforcement systems, teams and intelligence networks; and achieving price and 'brand' competitiveness in a crowded carbon offsets marketplace.

Although the issues listed in this paper are not comprehensive, they highlight major concerns and support the argument that a comprehensive and systematic approach to policy risk is likely to add value to the REDD+ implementation. The paper suggests that good management practice would separate risk management from policy or instrument development, and embed this aspect of good governance with a sufficient level of authority to ensure that the negative potentials are managed with a degree of vigour consistent with the importance of the issues.

\section{Introduction}

Much has been written about the Reducing Emissions from Deforestation and Forest Degradation, plus the role of Conservation, Sustainable Management of Forests and Enahancement of Forest Carbon Stocks (REDD+). However, the literature rarely responds to the questions: 'Is REDD+ a good thing, or a bad thing?' In part this reflects the 'capital versus labour' dimensions of the political contests that dominated the start of the $20^{\text {th }}$ Century, but in the greater part it reflects that the outcomes of REDD+ are dependent upon an array of often very complex contingencies.

Effective implementation of REDD+ requires significant investment in science and technical infrastructures (such as measurement and verification techniques and technologies), legal and institutional reforms, new financial instruments and transacting mechanisms, and the development of the capacities required to make this innovation work. It is clear that the failure to establish infrastructures and capacities will prejudice achievement of the REDD+ objectives.

Implementing REDD+ is intrinsically a multi-layered institutional and behavioural change program that is moving at a feverish pace. Major adjustments are required that span the roles of industry and finance

\footnotetext{
${ }^{1}$ The support of the Australian Research Council and other collaborators in the 'Next Generation Rural Landscape' research programme at the University of New England, Australia, is gratefully acknowledged.
} 
markets, states, regional governments, local communities and users of natural systems. Key aspects are being developed in parallel by groups of technical experts, ${ }^{2}$ with many NGO or government bodies providing advice from the sidelines.

Any change program generally takes time. Haste can result in notional agreements that lack true consensus or capacity to implement. New skills and technologies, policies and oversight arrangements are all subject to the limitations of skills and rates of learning. Everyday experience suggests that the application of new techniques is likely to be cumbersome, because naive users are hampered by their lack of the experiences through which efficiency is earned. The more novel and complex the tasks, the more that learning by doing is an important determinant of performance. Early actions are typically the most likely to fail.

The political timetable to deliver REDD+ is tight. The clash between the imperative for rapid implementation and the need for time to manage change is probably of great concern to those working to make REDD+ a success, but a consensus on the degree of change that can be realistically achieved within the available time has yet to emerge.

Innate complexity, limited development time, parallel development of interconnecting components, unavoidable inexperience and untried teams; these characteristics, when combined, suggest that REDD+ is a high risk enterprise that is more likely than not to encounter serious implementation difficulties. A failure in the early stages of implementation could undermine the credibility of the instrument for the longer term. If risk management at the early stage of REDD+ implementation fails, then REDD+ may be seen, in hindsight, as a naive and perhaps cavalier experiment.

\section{Pragmatics and instruments}

The success of any social change instrument relies largely upon the availability of resources, the capacity of those charged with administering the instrument and those whose behaviours are regulated, the strength of support or antagonism from the community, and factors beyond the normal concerns of legal or policy analysis. These factors apply whether the instrument is markets or regulation based. Markets and the instruments of capitalism are neither good nor bad in themselves. The people who use them are neither saints nor sinners because of their choice of instruments. Policed government regulation is not intrinsically more moral than market instruments, and vice versa. All forms of instruments fail, to varying degrees and for many reasons. They can fail to achieve their overt goals or they can create undesirable side effects. Policy failure is not an abnormal outcome of policy action!

The success of an instrument to influence change varies with the norms of the target community, and the integrity and capacity of the institutions responsible for implementation. The intelligence that is available to decision-makers will shape the transactions that take place. The lack of necessary information can prevent transactions that are essential to effective implementation. The success of an intervention can thus be seen as contingent upon context and resources; and upon the ways in which information and resources are manipulated by decision-makers who apply varied norms, preferences and decision-making approaches. ${ }^{3}$ Seen in this light, many types of risk exist in the policy environment.

Risk awareness lies at the heart of effective corporate governance in the private sector. ${ }^{4}$ It might be expected that the same would occur in the public sector. Major public sector strategic initiatives can impact on industry, the planet or the lives of vulnerable people. Unfortunately, in policy circles, disciplined risk management is not yet established as a norm of practice, even though policy failure or unanticipated outcomes are common. ${ }^{5}$

Sophisticated risk management takes a constructively pessimistic view of contingencies, identifying causes and effects, and the likelihood of contingencies occuring so that appropriate risk management strategies

\footnotetext{
2 Specifically: the Forest Carbon Partnership Facility, see <www.forestcarbonpartnership.org>; UN-REDD Programme, see <http://www.un-redd.org>; and Forest Investment Programme, see <www.climateinvestmentfunds.org/cif/node/5>.

3 P Martin and M Verbeek, Sustainability Strategies (Federation Press, 2006).

${ }^{4}$ See AS/NZS ISO 31000-2009 Risk Management - Principles and Guidelines, which replaces AS/NZS 4360-2004 Risk Management; and the international counterpart series ISO 31000 for standard methods $<$ http: / / www.iso.org/iso/catalogue_detail?csnumber=43170>

${ }^{5}$ A major initiative is the International Risk Governance Council, see Improving Governance of Systemic Risks <http: / / www.irgc.org>. For one potential methodology see P Martin and J Williams, 'Policy Risk Assessment' (Technical Report Series No 03/10, CRC for Irrigation Futures, March 2010) <http://www. irrigationfutures.org.au/news. asp?cat|D=9\&ID=1209>.
} 
can be used. This provides opportunities for controlling risk that might be an impediment to taking otherwise desirable action.

This paper highlights some of the many risks that the governance of REDD+ (in common with most environmental policy innovations) needs to pay attention to in order to avoid policy failure. Although the issues listed are not comprehensive, they highlight major concerns and support the argument that a comprehensive and systematic approach to policy risk is likely to add value to the REDD+ implementation.

There are positive steps being taken to identify and propose risk management actions in REDD+. These efforts are intensifying as implementation comes closer. At this stage, they do not seem to be integrated programmatically nor do they have the institutional power needed. However, there is still an opportunity, over the coming period, to establish a risk management team able to address both the 'big picture' architectural hazards and the more detailed implementation risks.

\section{Risk aspects of REDD+}

REDD+ is a mechanism under which developed countries (including industry in those countries) pay organisations in developing countries to conduct forest conservation and restoration projects for carbon offset purposes. The operations in supplier countries will be supervised by national agencies under locally specified institutional arrangements.

Arguably, it is a form of trans-national payment for ecological services (PES). PES programs have proven to be effective in developed countries, such as with payments for watershed services, ${ }^{6}$ which have included services for providing water quality, fish stocks, flood mitigation and landscape values. In the US, in 2008, PES transactions involved 16.4 million hectares of land with payments in excess of US\$1.3 billion. ${ }^{7}$ There are many markets for ecological services, including for carbon offsets. ${ }^{8}$ The scale of PES payments from existing schemes and the indicative commitments to REDD+ ought to give stakeholders confidence that large sums could be deployed for ecosystem protection in less developed economies should REDD+ achieve the confidence of the 'market'.

REDD + is, however, a uniquely complex form of PES. REDD+ arrangements aim to go beyond carbon offset, to achieve diverse ecological and social objectives in developing countries. Ideally the REDD+ scheme would ensure the maintenance of biodiverse and intact native forests and similar habitats, while advancing social justice, economic opportunity and social inclusion for disadvantaged (particularly Indigenous) people. The REDD+ vision is not of plantation monocultures merely offsetting the carbon emissions of rich companies in wealthy countries. Rather, the ambition is to tap the wealth of more developed countries to protect rich and diverse ecosystems in poorer countries, and thereby to enhance the economic and cultural lives of disadvantaged peoples.

REDD+ is intended to deliver a form of pooled carbon offset product through the aggregation of credits from different projects from different jurisdictions. These carbon credits will be traded in the voluntary offsets market, competing with other forms of carbon offset credits.

To achieve the ambitions of REDD+ requires overcoming many challenges.

1. Securitisation of carbon sequestration from diverse ecosystems in parts of the world where the relevant science and natural resource governance arrangements are at different stages of development;

2. Protection for complex non-carbon values, including biodiversity and social justice outcomes, in countries with different challenges and levels of performance on such issues;

3. Ensuring the integrity of the supply of credits from a large number of country jurisdictions, which will require the creation and management of many protected areas;

4. Multi-level administration and aggregation of tradable carbon interests, including aggregation at state and international levels;

\footnotetext{
6 Tracy Stanton, Marta Echavarria, Kate Hamilton and Caroline Ott, State of Watershed Payments: An Emerging Marketplace (Ecosystem Marketplace, 2010), 2; Kate A Brauman, Gretchen C Daily, T Ka'eo Duarte and HA Mooney, 'The Nature and Value of Ecosystem Services: An Overview Highlighting Hydrologic Services' (2007) 32 Annual Review of Environment and Resources 67, 68.

7 Stanton, above $\mathrm{n} 6$.

8 Steve Polasky, ‘Ecosystem Services Bibliography’ University of Minnesota <http://blog.lib.umn.edu/polasky/ecosystem>.
} 
5. Arrangements that must accommodate the social and economic imbalance of interests, such as between subsistence hunters and small scale farmers in disadvantaged countries and the largest and most powerful industrial corporations in the developed world;

6. The implementation of new methods for measurement and securitisation of interests, protection of ecosystems, reporting and transacting, and the establishment of the human and system capacity to do so reliably and at low cost;

7. Deployment of a platform of rules, administrative and enforcement systems, teams and intelligence networks to support the scheme; and

8. Achieving price and 'brand' competitiveness in a crowded carbon offsets marketplace.

Each jurisdiction is different in its culture and capacity to achieve desirable outcomes, norms and decisionmaking structures, and the social and economic challenges that it faces. Achieving the desired outcomes from the use of a REDD+ (or indeed any other form of market or regulatory instrument) is contingent on variables that go beyond the instrument itself. Put another way, in every instance of the use of REDD+, the outcomes are subject to risks and the risk profile will differ from jurisdiction to jurisdiction.

\section{Mangrove, peatland and wetland values}

The protection of mangrove, peatland and wetland ecosystems is of particular significance. The essential characteristics of these wet 'transitional' or 'ecotone' areas align well with the aspirations of REDD+. All are interfaces between land and water; a context conducive to the development of rich ecosystems. This characteristic delivers a bounty of ecosystem services and explains why mangroves, peatlands and wetlands have been traditionally favoured areas for human subsistence.

The Ramsar Secretariat ${ }^{9}$ lists the human service contributions of wetlands as including flood control, groundwater replenishment, shoreline stabilisation and storm protection, water purification, biodiversity, wetland products (or 'provisioning' services), cultural values, recreation and tourism. Provisioning and cultural values are the uses of most direct relevance to dependent communities but these ecosystems are as important to people in industrialised, advanced economies as to poorer jurisdictions. For example, Liu et al note that the freshwater and coastal wetlands of the State of New Jersey have been valued at well over US\$10B pa in 2006, making them most valuable source of ecosystem services in the State. ${ }^{10}$

The capacity of these habitats to be rich sources of food and fiber for non-industrialised communities are the same ones that that make these areas valuable for harmful exploitation, such as for agriculture, aquaculture, harvesting for marine and terrestrial resources (including peat), dumping of waste and pollutants, mining for minerals (such as salt or sand), and extraction or diversion of water. The exploitation may lead to an accumulation of harms such as seagrass removal by anchors of boats, proliferation of roadways and tracks, ingress of sediment, and overfishing. If REDD+ is to be effective, it requires curtailing many activities that could undermine the values for which the market currently pays. ${ }^{11}$

To stem such harms and conserve the systems requires programs to offset the economic opportunity that might have been gained from exploitation, coupled with strong protection measures implemented by governments or localised action. The opportunity for funds transfer from rich industrial stakeholders to less wealthy communities for the purposes of protection of such ecosystems, thus, has strategic significance. It may provide the economic incentive and the backing for effective regulation to enforce non-carbon governance standards for protected areas.

\section{Intrinsic risks of monetisation}

As a form of PES, REDD + carries the risks associated with the translation of non-quantified ecological and social values into quantified economic values, and the 'monetisation' of these values. Monetisation requires simple, readily measured units of exchange that can be secured and become the subject of contracts. With

\footnotetext{
${ }^{9}$ The Ramsar Convention on Wetland, Wetland Ecosystem Services - and Introduction <http://www.ramsar.org/pdf / info/services_00_e.pdf> and related factsheets < http://www.ramsar.org/cda/en/ramsar-pubs-info/main/ramsar/1-30$10340000>$

${ }^{10}$ Shuang Liu, Robert Costanza, Austin Troy, John D’Aagostino and Willam Mates, ‘Valuing New Jersey's Ecosystem Services and Natural Capital: A Spatially Explicit Benefit Transfer Approach' (2010) 45 Environmental Management 1271

11 The potential for effective REDD+ protection to provide precedents for improvements in resource governance more broadly is a possible complementary 'dividend' from the program.
} 
REDD+, the central unit is an amount of carbon offset, but there is the additional expectation that the means of delivery of this unit will safeguard or enhance other values. In effect the suppliers of credits will be promising to deliver the agreed amount of carbon offset in a way that provides complementary ecological and social safeguards. While the 'carbon' will be priced, other 'values' will be promised as conditions or assurances associated with the delivery of the carbon product. The content and the contractual reliability of these assurances are likely to be varied and 'signals' about these aspects will be homogenised as a result of the pooling of commoditised carbon credits.

At present, it is not clear how information about social and ecological governance issues will be communicated to buyers of credits or how they will be contractually enforced (if at all). Neither is it clear how much attention the market will pay to such details. Commodification limits consideration of non-priced values, as it 'strips out' non-commodity data in the transaction, ${ }^{12}$ such as data about production processes. Monetisation of some values potentially moves the focus away from 'best practice' management of social and environmental systems as a whole towards a focus on the monetised values of complex systems. Partial pricing of total systems naturally creates the potential that unpriced ecological or social values will be prejudiced. Carbon plantation monocultures and the clearing of rainforest for biofuels both illustrate the potential for perverse effects from initiatives intended to harness capitalist forces for ecological benefit. ${ }^{13}$

Property is exclusionary in nature. Property instruments must privilege those who have paid for the use of the resource over those who have not. Property rights are 'efficient' because they transfer control of a resource from the less economically competent to those who are more capable of exploiting the economic value. ${ }^{14}$ Ideally, the combination of exclusion and transfer to the economically competent leads to higher value for each unit of resource used, and provides the motivation to protect that resource against loss or destruction. Implicit in this calculation is the need to exclude those who lack proprietary interests from the 'property-ised' aspects of the resource. But protection of property often requires control over activities that might adversely impact the property interest even if such activities do not apparently form part of that interest. Thus, while carbon sequestration may be the subject of the property right, associated safeguards will extend the exclusionary effects of property to other non-purchased values. For example, fear of the potential for wildfire could lead to the exclusion of people who wish to forage for food or timber within a carbon-protected forest. The potential for this process to result in impacts on marginalised people pursuing their traditional uses is apparent. ${ }^{15}$

\section{Complexity and transaction costs}

There are strong social policy imperatives to avoid the risk that the protection of carbon property interests will result in the exclusion of traditional users from the landscapes upon which they depend. But the reality is that many uses are not protected at law, and arrangements that seek to preserve free use or access by non-owners might risk compromising the economic benefits of ownership, potentially prejudicing fundamentals of the governance conditions of the PES. Indeed, continuing a use may involve trespass or illegal activities once a carbon property interest is established. For example non-owners or non-participants in the REDD+ program might clear or burn areas protected for carbon sequestration, thus prejudicing biodiversity or other values that are ostensibly secured under a REDD+ arrangement. It may be that continuation of traditional uses can involve generation of ecological harms and social conflict and disadvantage.

Arrangements to safeguard the interests of non-owners and ecosystems will add managerial, administrative complexity and supervisory cost, and, therefore, increase transaction costs within the REDD+ mechanism. This is significant in terms of economic efficiency ${ }^{16}$ and impacts on the potential viability of the REDD+ initiative. Each additional cost erodes the margins achievable through transactions in the market for REDD+

\footnotetext{
${ }^{12}$ For identification the social justice risks of an ecosystem services market approach based upon consideration of their neo-liberal foundations and their application, see Kathleen McAfee, 'The Contradictory Logic of Global Ecosystem Services Markets Development and Change' (2012) 43(1) 105. For a critique of the social risks of all forms of intervention see Paul Martin, 'Embedding Social Justice in the Design of Environmental Regulation Poverty Alleviation and Environmental Protection' in Yves Le Bouthillier et al (eds), (Edward Elgar, 2012) 179.

${ }^{13}$ D B Lindenmayer et al, ‘Avoiding Bio-Perversity from Carbon Sequestration Solutions’ (2012) 5 Conservation Letters 28.

${ }^{14}$ Martin, above $\mathrm{n} 12$.

${ }^{15}$ For a jurisprudential examination of the issues see articles in (2012) 3(2) Journal of Human Rights and the Environment.

${ }^{16}$ Ronald H Coase, 'The Relevance of Transaction Costs in the Economic Analysis of Law' in Francesco Parisi and Charles K Rowley (eds), The Origins of Law and Economics: Essays by the Founding Fathers (Edward Elgar, 2005) 199.
} 
units, ${ }^{17}$ and, cumulatively, can have a significant effect on the pooled commodity. Governance and protection complexities can become an important source of transaction costs that will impact upon the cost of REDD+ units. ${ }^{18}$ Such costs may prove significant when considering that REDD+ units will be competing on price and other terms with other forms of carbon offset, and will be subject to commodity price pressures which will cap the ability to absorb transaction costs.

REDD+ is based upon a hierarchy of institutional arrangements, involving supplier-country entrepreneurs and managers and state agencies, a transnational transacting system and purchaser-country managers, and aggregators and purchasers. The processes of specification, measurement and securitisation of the carbon offset values are complex because of the diversity of ecosystems and contexts concerned, and consideration of non-carbon ecological and social values add greatly to the complexities and costs of transacting.

The challenges of designation and protection of tradeable interests; identification and matching of counterparties; consummating the transaction; and reporting, recording and evaluation of what is delivered are all potentially substantial, particularly in jurisdictions with under-developed environmental or financial market governance arrangements. ${ }^{19}$ Some transactions may be difficult to implement, and either insecure (generating uncertainty for the purchaser) or costly to securitise. This is particularly likely with the implementation of social justice and environmental protection arrangements, and their refinement over time, because these are matters requiring painstaking attention to detail and constant supervision.

There is ample evidence that impediments to transacting are fundamental to the performance of both market and regulatory actions. ${ }^{20}$ While it might be argued that implementation arrangements will be refined through time and experience, early failures could undermine the credibility of the institution, and thereby scuttle the potential of the REDD+ scheme.

\section{Purchaser-side issues}

As well as risks on the provider side of the transaction, there are risks on the buyer side. These are potentially significant if the REDD+ mechanism is to achieve the engagement of private industry in the purchase of REDD+ credits. The authors of the Munden Project ${ }^{21}$ suggest that the scheme is vulnerable because of the use of over-the-counter investment structures involving costly intermediation, potentially resulting in high costs and potential misallocation of resources. They argue that if the typical allocation of funds between suppliers and intermediaries in a commodity market (such as the market for grain or timber) were to be followed, less than one per cent of the total amounts invested in offset credits would go in payments to those who are operating the carbon-farming projects. ${ }^{22}$ Given the complexity and the uncertainties associated with the supply of carbon credits from a native forest, and the intermediation structure of the REDD+ market (involving governments, aggregators, project managers and industry purchasers with multiple counterparties) high transacting costs do seem likely.

Commodity suppliers are often price takers, and competition tends to force commodity prices down. This suggests that downward pressure on the price of REDD+ units may have a negative impact on the delivery of the social good outcomes that can not be well articulated in the carbon offset value of the units. That is, buyers of a carbon credit unit are unlikely to differentiate between units other than on price and volume. However, the supply cost of a unit will be affected by the costs of pursuing 'hidden' social justice and

${ }^{17} \mathrm{P}$ V Martin and J Shortle, 'Transaction Costs, Risks and Policy Failure' in Claudia Dias Soares (ed), Critical Issues in Environmental Taxation: International and Comparative Perspectives (Oxford University Press, 2010$)$ Vol VIII, 705.

${ }^{18} \mathrm{See}$, eg, A Dermawan et al, 'Preventing the Risk of Corruption in REDD+ in Indonesia' (Working Paper 80, United Nations Office on Drugs and Crime, and Center for International Forestry Research, 2011).

${ }^{19}$ R N Stavins, 'Transaction Costs and Tradeable Permits' (1995) 29 Journal of Environmental Economics and Management 133 ,146: 'The general message for public policy that arises when we begin to consider the presence of transaction costs in markets for tradeable permits is that "the devil is in the details". Finally, with transaction costs as with other departures from frictionless markets, greater attention should be paid to the details of design of specific systems, in order to lessen the risk of overselling these policy ideas and in order to create systems that stand a chance of being implemented successfully'.

${ }^{20}$ D W Bromley, 'Rethinking Markets' (1997) 79 (Proceedings Issue No 5) American Journal of Agricultural Economics 1383; B D Richman and J T Macher, 'Transaction Cost Economics: An Assessment of Empirical Research in the Social Sciences' (2006) Duke Law School Legal Studies Research Paper 115; Stavins, above n 19.

21 The Munden Project, REDD and Forest Carbon: Market-Based Critique and Recommendations (7 March 2011) <http://www.rightsandresources.org/documents/files/doc_2215.pdf>.

22 Ibid 8. 
ecological outcomes. Cost cutting of social and biodiversity guarantees could be the probable response of suppliers under economic pressure because the marketplace signals about this depreciation would be hidden within the pooling of units and are likely to be more delayed than any signals of carbon sequestration failures.

The authors of the Munden Project point to the characteristic of commodity markets to evolve towards monopsony structures, with the imbalance of power benefitting the purchaser over the supplier. Information about the value to a supplier of social or biodiversity outcomes will not be reflected in the units of carbon purchased by the purchaser unless some other differentiation signals can be built into the system. How will REDD+ units be promoted so as to reduce the masking effects of commodification and pooling on the preferences of purchasers? It is difficult to see how an efficient mechanism can be created that will allow the price of pooled carbon units to properly reflect unpriced social values other than through a substantial investment in marketplace differentiation.

Differentiating REDD+ carbon units from other sources of carbon offset is one aspect of the commodification/differentiation issue. The other is the potential for 'superior' suppliers of units (at a project and jurisdiction level) to be disadvantaged through non-distinctiveness within the system. The REDD+ 'product' is drawn from varied ecosystems and jurisdictional contexts, all of which impact upon the extent and reliability of the value that will be delivered. Failure to effectively securitise all aspects of REDD+ units may translate into integrity and credibility loss, which in turn could undermine the market.

Buyers can create ways of managing risks of specification or reliability of delivery. These include ranking suppliers or products, certification or the use of standards, discounting or use of insurance. ${ }^{23}$ Over time, the implementation of such risk management strategies might lead to those projects that are located in less trusted jurisdictions or which are 'burdened' with costly unpriced social justice or cultural values being less attractive. ${ }^{24}$ Selection around reliability of delivery may be an impediment for those countries plagued by weak environmental governance but where REDD+ funding might have the most transformative value. Aggregation and commodification may mean that the more reliable performers in terms of delivery of social and ecological outcomes may effectively carry the less reliable suppliers. The potential for supplier conflict over this issue should not be discounted as a risk.

Once environmental values are commoditised and become the subject of private entrepreneurship, the outcomes are not always predictable or able to be controlled, even by governments. The international trade in carbon units will be subject to free trade conventions that limit government actions that discriminate between suppliers of ostensibly comparable products. Coupled with this, is the potential for derivative markets to generate unanticipated financial pressures on the underlying, securitsed resource. The effect of derivatives entrepreneurship has been demonstrated with the collapse of housing and finance markets and is present with PES schemes including those for carbon. ${ }^{25}$ Free market entrepreneurship could pose risks to REDD+ even after it is established unless risk is anticipated and managed from the outset.

\section{Supply-side risks to non-carbon outcomes}

There are many threats to the achievement of the social equity goals of REDD+. ${ }^{26}$ One that has been highlighted by a number of authors is that the protective arrangements for managing REDD+ designated forests could act counter to moves to increase community management of natural resources. For a state administration charged with managing lands that are subject to carbon credits and associated caveats at low cost, the temptation for centralisation of control may be strong. The new economic incentive to

\footnotetext{
${ }^{23}$ See, eg, the Gold Standard verification process <http://www.cdmgoldstandard.org/about-us/why-gs>; or see Forum for the Future, 'The Potential for Risk Mitigation Mechanisms to Facilitate Private Sector Investment in REDD+ investments' Forest Investment Review (2009) 95, ch 4 <http://www.forumforthefuture.org/sites/default/files/images/ Forum/Projects/Forest-Investment-Review/Chapter4_FIR.pdf>.

${ }^{24}$ See Munden Project, above n 21, 20-22, for a discussion of volatility and risk pricing effects.

${ }^{25}$ Fredrick Kaufman, 'Wall Street's Thirst for Water' (2012) 490 Nature 469.

${ }^{26}$ For a recent summary see 'Is Equitable REDD+ Possible: The Role of Social Safeguards, Standards and Impact Assessment in Reducing Risks and Enhancing Outcomes' (July 2012) Forest Trends <http: / /www. foresttrends.org/documents/files/doc_3232.pdf>. This report proposes a set of participatory arrangements to ensure proper evaluation of these risks
} 
control un-developed lands that may not have previously earned an income may contribute to that pressure. $^{27}$

REDD+ relies upon the capacity of supply country administrations to ensure the integrity of the supply of carbon units. As has been noted above, there is a great diversity in the political philosophies, governance arrangements and institutional capacity of different jurisdictions, and it should be anticipated that this might translate into variable implementation of REDD+ requirements. ${ }^{28}$ Many jurisdictions which are expected to implement securitisation and oversight of forest governance face capacity challenges, and the affected communities are, in many cases, struggling. The specification, measurement and securitisation challenges implicit in REDD+ are complex. Failure to meet these requirements could undermine the ability to participate in the REDD+ market, generate conflict between suppliers and perhaps undermine the market as a whole. ${ }^{29}$

Huettner's summary of identified risks from the literature provides a suitable synthesis of supply side concerns. ${ }^{30}$ Paraphrased and expanded, these are:

1. That the lands most suitable for carbon-offset-based protection may not be those that are most valuable for ecological (or, presumably social) protection. The protection of lands for REDD+ reasons might increase demands upon other lands that are intrinsically significant from an ecological or social justice perspective.

2. Creation of REDD+ 'reserves' may add to land scarcity, driving up land values and disadvantaging marginal or excluded groups in society. This is particularly relevant to agrarian communities whose traditional uses involve relocation within forested or other REDD+ relevant landscapes. Land scarcity could also feed into food scarcity and increased food prices.

3. Because the denominator of value for REDD + units is carbon offset, the potential exists that lands will be managed to maximise this value. This may depreciate other ecological or social values. The potential for conversion into plantation monocultures is the more extreme version of this risk.

4. Because only the carbon values are 'captured' in the economic valuation of these lands, there is no intrinsic reason why other values may not continue to be subject to depreciation. Poaching of wildlife or habitat is not inherently prevented through the REDD+ mechanism, nor is there necessarily any alignment between REDD+ protected land boundaries and biodiversity or social protection. Along the same lines, REDD+ does not necessarily translate into improved policing or protection of other values, and so logging or poaching may continue in nominally protected areas.

5. REDD+ 'reserves' may fuel land use conflicts. At its worst, such reserves could exclude traditional (particularly indigenous) land users. There is no mechanism embedded in REDD+ to ensure participation and social justice aspects of land management are well managed, though the evaluation approach discussed below does recognise this risk.

6. Poor governance or a failure to put in place effective wealth-transfer mechanisms could result in the economic benefits being mal-distributed to the state or elites. Unreliable governance conditions are present in a number of the relevant jurisdictions.

7. The institutional arrangements for REDD + are not robust against changes in opportunity costs of protection compared to other exploitative uses. Should alternative uses become more valuable, the continued use of lands for REDD+ purposes is not assured. The author also identified the risk of high transaction costs (detailed earlier in this paper) to make smaller-scale REDD+ projects non-viable.

Governance issues emerged as the most significant perceived risks. This is consistent with other studies and international experience. A detailed examination of implementation challenges for Indonesia is

\footnotetext{
${ }^{27}$ See also Matt Sommerville, 'Land Tenure and REDD: Risks to Property Rights and Opportunities for Economic Growth' (Briefing Paper \#11. USAID, August 2011) <http://usaidlandtenure.net/issue-brief/land-tenure-and-redd>.

${ }^{28} \mathrm{~N}$ Gunningham and D Sinclair, 'Non-Point Pollution, Voluntarism and Policy Failure: Lessons for the Swan-Canning' (2004) 1 Environmental Protection Legislation Journal; L I Pahl, 'Adoption of Environmental Assurance in Pastoral Industry Supply Chains - Market Failure and Beyond' (2007) 47 Australian Journal of Experimental Agriculture 233; S M Whitten, A Coggan and A G Reeson, 'Putting theory into practice: Market Failure and Market Based Instruments (MBIs)' (Working Paper 2 in the Socio-Economics and the Environment in Discussion, CSIRO, 2007) <http://www.csiro.au/ resources/SEEDPaper2.html>. For some international experiences see M G Faure 'Instruments for Environmental Governance: What works' in P Martin et al (eds), Environmental Governance and Sustainability (Edward Elgar, 2012); R N Stavins, 'Experience with Market-Based Environmental Policy Instruments' (Discussion Paper 01-58 Resources for the Future, 2001).

${ }^{29}$ See Martin and Shortle above n 17 for examples of environmental market failures attributable to information failures.

${ }^{30}$ Michael Huettner, 'Risks and Opportunities of REDD+ Implementation for Environmental Integrity and Socio-Economic Compatibility’ (2012) 15 (1) Environmental Science \& Policy 4.
} 
illustrative ${ }^{31}$ Interestingly, that study suggests that the major governance risk is not on the implementation front line, but rather during the policy making process when opportunities for institutionalised distortion or openings for later corruption are presented. ${ }^{32}$

The UN REDD programme published six principles and related criteria for the assessment of risks to social and environmental goals of the program in late 2011. These provide a good indication of the identified risks and the direction of thinking about socio-environmental issues: ${ }^{33}$

Principle 1: Apply norms of democratic governance, including those reflected in national commitments and Multilateral Agreements.

Criterion 1. Ensure the integrity and transparency of fiduciary and fund management systems.

Criterion 2. Ensure accountability and legitimacy of all bodies representing stakeholders, including through establishing responsive national feedback, complaints and grievance mechanisms, amongst others.

Criterion 3. Ensure transparency and accessibility of all information related to REDD+, including active dissemination among relevant stakeholders.

Criterion 4. Ensure the full and effective participation of relevant stakeholders, in particular, indigenous peoples and other forest dependent communities, with special attention to the most vulnerable and marginalised groups.

Criterion 5. Promote coordination, efficiency and effectiveness, including cooperation across sectors and in the enforcement of laws.

Criterion 6. Ensure the rule of law and access to justice.

Principle 2: Respect and protect stakeholder rights, including human rights, statutory and customary rights, and collective rights.

Criterion 7. Respect and promote the recognition and exercise of equitable land tenure and carbon rights by indigenous peoples and other local communities.

Criterion 8. Promote and enhance gender equality, gender equity and women's empowerment.

Criterion 9. Seek free, prior and informed consent of indigenous peoples and other forest dependent communities and respect and uphold the decision taken (whether consent is given or withheld).

Criterion 10. Ensure there is no involuntary resettlement as a result of REDD+.

Criterion 11. Respect and protect traditional knowledge and cultural heritage and practices.

Principle 3: Promote and enhance forests' contribution to sustainable livelihoods.

Criterion 12. Ensure equitable, non-discriminatory and transparent benefit sharing and distribution among relevant stakeholders with special attention to the most vulnerable and marginalised groups.

Criterion 13. Protect and enhance, while minimizing adverse impacts on, economic, social and political well being of relevant stakeholders with special attention to the most vulnerable and marginalised groups.

Principle 4: Contribute to low-carbon, climate-resilient sustainable development policy, consistent with national development strategies, national forest programmes and commitments under international conventions and agreements.

Criterion 14. Ensure consistency with and contribution to national climate policy objectives, including mitigation and adaptation strategies and international commitments.

Criterion 15. Address the risk of reversals of REDD+ achievements, including potential future risks to forest carbon stocks and other benefits to ensure the efficiency and effectiveness of REDD+.

Criterion 16. Ensure consistency with and contribution to national poverty reduction strategies and other sustainable development goals (including those outlined under the Millennium Development Goals framework), including alignment with ministries' and subnational strategies and plans that may have an impact on, or be affected by the forest sector and/or land use change.

Criterion 17. Ensure consistency with and contribution to national biodiversity conservation policies, other environmental and natural resource management policy objectives, national forest programs, and international commitments.

\footnotetext{
${ }^{31}$ Dermawan et al, above n 18

32 Ibid.

${ }^{33}$ UN-REDD Programme, 'Draft Social and Environmental Principles and Criteria - Benefit and Risks Tool' (SEPC-BeRT) instructions available at <http://www.unredd.net/index.php?option=com_docman\&task=doc_ download\&gid=6380\&ltemid=53>, with links to the spreadsheet format.
} 
Principle 5: Protect natural forest from degradation and/or conversion to other land uses, including plantation forest.

Criterion 18. Ensure that REDD+ activities do not cause the conversion of natural forest to other land uses, including plantation forest, and make reducing conversion due to other causes (e.g. agriculture, timber and fuel wood extraction, infrastructure development) a REDD+ priority.

Criterion 19. Minimise degradation of natural forest by REDD+ activities and make reducing degradation due to other causes (e.g. agriculture, timber and fuel wood extraction, infrastructure development) a REDD+ priority.

Criterion 20. Minimise indirect land-use change impacts of REDD+ activities on forest carbon stocks, biodiversity and other ecosystem services (including impacts of extractive activities).

Principle 6: Maintain and enhance multiple functions of forest to deliver benefits including biodiversity conservation and ecosystem services.

Criterion 21. Ensure that land-use planning for REDD+ explicitly takes account of ecosystem services and biodiversity conservation in relation to local and other stakeholders' values, and potential synergies and trade-offs between different benefits.

Criterion 22. Ensure that planted and natural forests are managed to maintain and enhance ecosystem services and biodiversity important in both local and national contexts.

Principle 7: Minimise adverse impacts (direct and indirect) on non-forest ecosystem services and biodiversity.

Criterion 23. Minimise adverse impacts on carbon stocks, biodiversity and other ecosystem services of non-forest ecosystems resulting directly from REDD+ activities (such as afforestation).

Criterion 24. Minimise indirect land-use change impacts on carbon stocks, biodiversity and other ecosystem services of non-forest ecosystems (including impacts of extractive activities).

Criterion 25. Minimise other adverse indirect impacts on biodiversity and carbon stocks of non-forest ecosystems, such as those resulting from intensification of land use.

This draft protocol is a first step towards systemic risk identification, and it suggests that the UNE-REDD programme has heard and understood many of the concerns expressed by different stakeholders. Both the criteria and the more detailed guiding questions within the template are likely to yield useful information about relevant administrative structures in various countries. Without wishing in any way to be negative about this important development, it is hoped that this is only a small part of a more comprehensive approach to risk identification and management.

\section{Policy risk management strategies and REDD+}

REDD+ is an ambitious advance in the use of payments for environmental services. REDD+ is highly innovative in seeking to address dimensions of trans-nationality, ecological integrity and social justice on the back of a payment for a commodity environmental service (carbon offset). Everyone concerned has an interest in seeing REDD+ work, even those who are sceptical or critical. However a desire to see it work should not cause advocates to minimise the many challenging risks to that success. Indeed, the desire to see it work is the strongest possible reason for taking a careful approach to risk management.

To date, whilst an increasing variety of risks have been raised by different organisations and actions taken to address some them, the process seems to have been largely ad hoc, or at least less robust and overt than seems to be required given the importance of the initiative and the types of adverse consequences that may be visited upon already disadvantaged states and communities, and threatened habitats.

As well as the risk information to be gathered through the use of the benefits and risks tool, other risks work is being conducted. The International Union of Forest Research Organisations (IUFRO) has conducted research into mechanisms for the protection of social values. ${ }^{34}$ Preliminary information suggests that the paper will highlight many of the same issues that are outlined in this paper, highlighting that: the difference between positive and negative outcomes will depend largely upon implementation effectiveness; effectiveness depends in no small degree upon finding solutions to detailed problems; and issues and solutions will be very jurisdiction and socio-ecosystem dependent.

${ }^{34}$ International Union of Forest Research Organizations, CBD Briefing Note, (15 October 2012). For the full report see John A Parrotta, Christoph Wildburger and Stephanie Mansourian, 'Understanding Relationships Between Biodiversity, Carbon, Forests and People: The Key to Achieving REDD+ Objectives. A global assessment report' (IUFRO World Series Vol 31, 2012) <http://www.iufro.org/download/file/9212/5303/ws31_pdf>. 
What is needed is a high-quality task force that is adequately resourced and which contains people with expertise in risk strategy (not only risk administration), who are focused upon the development of an integrated risk management program for implementation of REDD+. There are many contingencies that need to be managed for this important initiative to be successful, and the existing institutional arrangements are currently structurally fragmented. As there are many people and organisations involved, and significant potential conflicts of interest that intersect with the project implementation tasks, it is important that the risk management task force have a sufficient level of authority to ensure that action is taken prior to the emergence of adverse events, and that an adaptive approach is taken to rapidly learn from the inevitable failures to ensure that these do not compromise the ultimate achievement of the REDD+ goals. 